\title{
The effect of conceptual complexity on information search in a complex problem-solving task
}

\author{
MARVIN KARLINS, THOMAS COFFMAN, HELMUT LAMM AND HAROLD SCHRODER
}

PRINCETON UNIVERSITY ${ }^{1}$

Individuals varying in their level of integrative complexity (Schroder, Driver, E Streufert, 1966) requested information about a novel environment for use in solving a complex problem. Ss who are integratively complex are more active in this type of learning task (ask more questions) and request different types of information than their integratively simple counterparts.

A theoretical framework which views individuals and groups, in interaction with their environment, as active information-processing systems is being developed by Schroder and his associates (Harvey, Hunt, \& Schroder, 1961; Schroder, Driver, \& Streufert, 1966). In this model, any psychological situation may be simply described as a range of stimuli which are "read" and transformed via mediating processes into a set of behavioral outputs or responses. There are several characteristics that describe the functioning of these mediating processes, the most important of which is the information-processing of the system. Over a given range of stimuli, information-processing ability varies among individuals and is measured in terms of its integrative complexity. Higher integrative complexity refers to a greater number of perceptual categories for receiving information about the world, and more conceptual or combinatory rules for organizing such units of information. Integrative complexity is described as varying along a continuum that represents gradations in information-processing ability. It is measured by the Paragraph Completion Inventory (Schroder \& Streufert, 1962; Schroder, Driver, \& Streufert, 1966, Ch. 12), a semi-projective test that requires $\mathrm{Ss}$ to write three-sentence responses to stimuli that create discrepancy and uncertainty.

Utilizing the Schroderian conceptual systems approach, one can make certain predictions about the way in which people will search for information in problem-solving situations. In complex problem-solving tasks it is expected that integratively complex individuals will be able to bring a greater number of dimensions to bear on a given problem and generate more perspectives that link specific dimensions with task considerations. It is predicted that integratively complex individuals, in comparison to integratively simple individuals, will be more active in their information search (ask more questions), and will request different types of information in dealing with situations that require the generation of perspectives. The Navy Tactical Simulation (NATS) will be used as a means of testing these contentions.

\section{Method}

Subjects. Twenty-four Ss, matched on age and intelligence, and varying in conceptual level (12 integratively simple, 12 integratively complex) participated in the experiment. Intelligence was assessed by the Wonderlic Personnel Inventory (Wonderlic, 1952), an intelligence test that correlates .87 with the Otis Intelligence Scale. Integrative Complexity was measured by the Paragraph Completion Inventory.

The Experimental Task. $\mathrm{S}$ was asked to pretend he was an officer in charge of a task force proceeding to a destination in enemy-held territory. His principal task was to keep his fleet intact until it reached its destination, and to do this it was necessary for him to: (a) maintain effective vigilance in and around his task force; (b) keep the task force undiscovered as long as possible; (c) assure readiness to defend his forces from enemy attack by effective gathering and analysis of information based on radar reports. S's job was further complicated by the fact that he began the task with no knowledge of the components of his own or enemy forces. Following the model already developed with the Community Development Exercise (Karlins \& Lamm, 1965; Karlins, 1966), the present task required $S$ to gain his information about the task force situation through active information search: written questions submitted to the experimental staff. The answers to his questions (one or two typewritten sentences) were returned to him on the back of coded IBM cards. S understood that the only way he could obtain answer cards was by asking questions about his task; the number and type of answer cards $S$ could receive was entirely determined by the number and type of questions he asked.

There were 101 answer cards, prepared in advance of the experiment, that $\mathrm{S}$ could receive in the $45 \mathrm{~min}$. allotted to information request about the task force environment. These answer cards contained information relevant to five aspects of the task force environment: (a) the nature and distinguishing characteristics of various objects which could be picked up and identified with task force radar; (b) the capabilities of various types of radar utilized by fleet ships and planes; (c) the operational characteristics of radar; (d) information concerning the enemy (e.g., how many ships does the enemy have); and (e) general information on own forces and surrounding environment.

Experimental Hypotheses. (a) There is some evidence (Dold, 1964; Driver, 1960; Sieber \& Lanzetta, 1964; Tuckman, 1964) that integratively complex individuals, 
in comparison with Ss lower in integrative complexity, are more active in their information search. In the Navy Tactical Simulation an objective measure of information search is readily available, if one assumes that such activity can be reflected in the number of questions asked by $\mathrm{S}$ during the $45 \mathrm{~min}$. information acquisition period. It is important to point out that information search cannot be construed as a general measure of integrative complexity of information processing in a particular area. A person could use his information search prerogatives to reduce uncertainty, eliminate conflict and ward off diversity in his environment-goals characterizing a simple system. In this unstructured task, with many degrees of freedom and a good deal of complexity, it is argued that the integratively complex individual will ask more questions because he has more perspectives to assist him in generating questions. It is hypothesized that integratively complex Ss, in comparison with integratively simple $\mathrm{Ss}$, will undertake more extensive information search as measured by the total number of questions asked during the information acquisition period. (b) In the context of the present study, the task-relevant material may be seen logically to constitute two levels of understanding. Level $I$ is the factual details: radar ranges and capabilities, own forces' components, and components of the enemy forces. Level II is the problem of actual detection and identification of objects picked up by radar. Competent performance at each successive level indicates corresponding ability to generate increasingly higher-order rules for dealing with information acquisition. It is hypothesized that integratively complex individuals, in contrast with integratively simple individuals, will request significantly more items dealing with the detection of foreign objects and their properties through the use of radar (level II questioning), and will therefore ask questions receiving answers from the first information category (the nature and distinguishing characteristics of various objects which could be picked up and identified with task force radar). Further, integratively simple Ss will ask more questions about the enemy directly (level I functioning), receiving more answer cards out of the fourth information category (information concerning the enemy).

\section{Resulis and Discussion}

All hypotheses were analyzed for significance using one-tailed t-tests. The $t$-values for the experimental hypotheses (number of questions asked, types of questions asked) were generally supportive of the predictions (one finding was marginally significant). Integratively complex individuals, in comparison to integratively simple individuals: (a) are more active in their information search, as reflected in the number of questions asked in a complex problem-solving task $(t=2.79$, $p<.01)$; (b) request more informational answer cards dealing with detection of objects through the use of radar $(t=1.47, p<.07)$; and (c) request fewer answer cards dealing with the enemy directly $(t=1.72, p<.05)$. It is noted, in keeping with experimental predictions, that integratively simple Ss asked the greatest proportion of their questions about their own and enemy forces directly, while the integratively complex Ss were more concerned with the means of identifying foreign objects, the properties of these objects, and the use of search equipment in the task force situation. This concern with the search aspects of the environment is in keeping with findings reported by Streufert \& Schroder (1965).

The findings of the present investigation lend credence to the notion that when Ss varying in integrative complexity are allowed to learn a task by active manipulation of the environment, they approach that environment and the learning task differently. Ss who are integratively complex are more active in this interdependent environment (ask more questions) and ask for different types of information than their integratively simple counterparts. Thus, it seems that the methods by which individuals learn and the information they want to learn varies according to the integrative complexity of the learner, and that these variations in learning are expressed in their information search in an environment with enough complexity and freedom to allow for such performance variation.

\section{References}

Dold, A. W., III. The effects of group composition and stress on heterogeneous teams in a simulated industrial setting. Unpublished senior thesis, Princeton University, 1964.

Driver, M. J. The relationship between abstractness of conceptual functioning and group performance in a complex decision-making environment. Unpublished master's thesis, Princeton University, 1960.

Harvey, O. J., Hunt, D. E., \& Schroder, H. M. Conceptual systems and personality organization. New York: John Wiley, 1961.

Karlins, M. Conceptual complexity and remote associative proficiency as creativity variables in a complex problem-solving task. ONR Technical Report, Princeton University, 1966.

Karlins, M., \& Lamm, H. The community development task: a theoretical validation of measures. Appendix 1, Peace Corps Assessment Program, 1965.

Schroder, H. M., Driver, M. J., \& Streufert, S. Human information processing: individuals and groups in complex social situations. New York: Holt, Rinehart \& Winston, 1966.

Schroder, H. M., \& Streufert, S. The measurement of four systems of personality structure varying in level of abstractness: Sentence completion method. ONR Technical Report, Princeton University, 1962.

Sieber, J. E., \& Lanzetta, J. T. Conflict and conceptual structure as determinants of decision making behavior. J. Pers., 1964, 32, 622-641.

Streufert, S., \& Schroder, H. M. Conceptual structure, environmental complexity and task performance. J. exp. Res. Pers., 1965, 1, 132-137.

Tuckman, B. W. Personality structure, group composition, and group functioning. Sociometry, 1964, 27, No. 4.

\section{Note}

1. Research done under ONR Research Contract No. 1858 (42). We thank Dr. Bertram L. Koslin for helpful suggestions. 